\title{
O envelhecer na visão do profissional de Educação Física atuante em academia de ginástica: corpo e profissão
}

\author{
Diego Costa Freitas* \\ Alexandre Palma** \\ Carlos de Andrade Coelho Filho*** \\ Silvia Maria Agatti Lüdorf****
}

\begin{abstract}
Resumo: O presente estudo se propõe a investigar como o profissional de Educação Física atuante em academia de ginástica concebe e lida com o seu envelhecimento, além de discutir eventuais relações no tocante ao envelhecimento, ao corpo e ao mercado de trabalho das academias de ginástica. Os dados foram obtidos por meio de entrevistas semiestruturadas. Deixar de ser o modelo jovem e saudável apreciado no âmbito das academias emerge negativamente a esses profissionais, que buscam no conhecimento adquirido na profissão encobrir estereótipos associados ao envelhecimento. Dessa forma acreditam aumentar as chances de permanência nesse mercado.
\end{abstract}

Palavras-chave: Academias de ginástica. Docentes. Educação Física. Envelhecimento. Corpo.

\section{INTRODUÇÃo}

Um modelo corporal ligado a parâmetros baseados na prática de atividade física adquire cada vez mais centralidade em tempos atuais (ORTEGA, 2010). O exercício físico assume valor central na construção do corpo: melhora a forma física, diminui a gordura corporal e expõe os músculos (LUPTON, 2000).

\footnotetext{
* Universidade Federal do Rio de janeiro, Escola de Educação Física e Desportos, Rio de Janeiro, RJ, Brasil. E-mail: diego.costafreitas@hotmail.com

** Universidade Federal do Rio de janeiro, Escola de Educação Física e Desportos, Rio de Janeiro, RJ. Brasil. E-mail: palma_alexandre@yahoo.com.br

*** Universidade Federal de Juiz de Fora, Faculdade de Educação Física e Desportos, Juiz de Fora, MG. Brasil. E-mail: carlos.coelho@ufjf.edu.br

**** Universidade Federal do Rio de janeiro, Escola de Educação Física e Desportos, Rio de Janeiro, RJ. Brasil. E-mail: sagatti.rlk@terra.com.br
} 
Nessa atual conjuntura, as práticas corporais, juntamente com as academias de ginástica, ambiente privilegiado para prática de exercícios físicos, ganham cada vez mais espaço (FREITAS et al., 2011; ROJAS, 2003; MARCELLINO, 2003; SASSATELLI, 1999). A partir de 1970, as academias de ginástica proliferaram consideravelmente, associadas principalmente à busca por uma melhora na estética corporal (NOVAES, 2001). Mais recentemente, de acordo com Crossley (2006), além dos aspectos relacionados à aparência, as academias de ginástica são um local para elevar a autoestima e fazer amizades. Outro conceito sempre presente no âmbito das academias é o de saúde, normalmente atrelado ao de qualidade de vida (LIZ et al., 2010; TOSCANO, 2001).

Diante desse quadro, um dos principais atores da academia de ginástica, o profissional de Educação Física, é visto como figura influente nesse ambiente onde as questões corporais se colocam afloradas (FREITAS et al., 2011a). Normalmente, sua figura é associada à de um profissional jovem, saudável e exuberante em seus aspectos físicos. Para Palma et al. (2007), tem sido exigido que a figura do profissional de Educação Física atuante em academia seja de um jovem com vestuário esportivo da moda, que necessita manter uma forma atlética e ser imune aos problemas de saúde, uma vez que sua aparência e disposição física devem remeter para certo ideal de corpo.

Já com relação à carreira no âmbito das academias, estudos apontam que aspectos como jovialidade e aparência podem ser até mais valorizados do que a experiência e o conhecimento técnico na conquista de prestígio e estabilidade (VILHENA et al., 2012; PALMA ; ASSIS, 2005; ANTUNES, 2003; COELHO FILHO, 2001; 1997). Porém, até onde se pode verificar, apenas Coelho Filho (2005) e Lüdorf e Ortega (2013) investigaram a influência destes aspectos (jovialidade, aparência e, especialmente, o envelhecimento) no que diz respeito à estabilidade e às expectativas de ascensão do profissional de Educação Física no mercado das academias de ginástica. Observa-se, portanto,

Movimento, Porto Alegre, v. 20, n. 4, p. 1523-1541, out./dez. de 2014. 
uma lacuna de conhecimento, principalmente com relação a compreender melhor o trabalho do profissional de Educação Física nas academias com o avançar da idade.

Há de se destacar a importância de se estudar questões ligadas ao corpo e à aparência do profissional de Educação Física atuante em academias de ginástica como, por exemplo, as associadas ao seu envelhecimento, devido principalmente: 1) ao seu destaque e à sua influência nesse meio; 2) à valorização da aparência superficial do corpo no interior dessas instituições; 3) à representatividade crescente das academias de ginástica como centros de convivência na sociedade contemporânea. Assim, a produção e divulgação do conhecimento científico acerca do tema podem contribuir para ampliar os debates, até então incipientes, tanto no âmbito acadêmico quanto no da população em geral.

Desse modo, o presente estudo se propõe a investigar como o profissional de Educação Física atuante em academia de ginástica concebe e lida com o seu envelhecimento, além de discutir eventuais relações no tocante ao envelhecimento, ao corpo e ao mercado de trabalho das academias de ginástica.

\section{Procedimentos metodológicos}

A presente pesquisa é de natureza qualitativa, pois busca compreender não apenas o fenômeno em si, mas principalmente seus significados num determinado contexto social, valorizando o processo, e não apenas o resultado (TURATO, 2005).

Dentro dessa concepção de pesquisa, a seleção dos sujeitos que irão compor o corpus de investigação é um ponto determinante em sua construção. Duarte (2002, p.141) alega que "[...] a descrição e delimitação da população base, ou seja, dos sujeitos a serem entrevistados, assim como o seu grau de representatividade no grupo social em estudo, constituem um problema a ser imediatamente enfrentado [...]". Desse modo, a pesquisa foi realizada com base nas orientações de Gaskell (2003)

Movimento, Porto Alegre, v. 20, n. 4, p. 1523-1541, out./dez. de 2014. 
de ampliar a diversidade de opiniões, bem como nas indicações de Bauer e Aarts (2003), uma vez que se tenta compreender a variedade de representações das pessoas no seu mundo vivencial.

Os critérios considerados para a seleção dos profissionais foram: ser graduado em Educação Física e atuar no mercado de academia de ginástica com experiência mínima de 10 anos. O tempo de atuação no mercado se justifica mediante a compreensão de que as experiências vividas ao longo dos anos de trabalho podem favorecer o aprofundamento das reflexões e/ou riqueza do discurso.

Importante destacar que houve dificuldade em encontrar sujeitos que se encaixassem no critério de tempo de trabalho em academias. Além disso, foi detectada certa resistência em participar por se tratar de uma pesquisa sobre uma temática sensível, como o envelhecimento, fato este percebido também por Goldenberg (2008) e Lüdorf e Ortega (2013). Desse modo, a seleção dos sujeitos foi realizada principalmente por conveniência. Os entrevistados, de um modo geral, trabalhavam em uma ou mais academias de ginástica de grande e médio porte localizadas na zona sul da cidade do Rio de Janeiro; importa ainda observar que, numa perspectiva geral, atuavam em academias diferentes. Eram instrutores de musculação, atuavam com ginástica localizada (e variações) ou como personal trainer.

O número de entrevistas foi determinado no decorrer da pesquisa, considerando a profundidade e a "originalidade" dos dados contidos em cada uma delas (DUARTE, 2002). Foram realizadas 12 entrevistas com profissionais de Educação Física, sendo 10 homens e duas mulheres, de faixa etária compreendida entre 35 e 61 anos, e graduação obtida no período de 10 a 38 anos atrás, como poderá ser observado no QUADRO 1.

Movimento, Porto Alegre, v. 20, n. 4, p. 1523-1541, out./dez. de 2014. 
Quadro 1 - Perfil dos entrevistados.

\begin{tabular}{|c|c|c|c|}
\hline $\begin{array}{c}\text { Profissionais de } \\
\text { Educação Física* }\end{array}$ & $\begin{array}{c}\text { Ano de forma- } \\
\text { ção }\end{array}$ & $\begin{array}{c}\text { Tempo de ex- } \\
\text { periência em } \\
\text { academias (em } \\
\text { anos) }\end{array}$ & Idade \\
\hline M2 & 2001 & 10 & 40 \\
\hline M22 & 1980 & 29 & 53 \\
\hline H2 & 1987 & 23 & 45 \\
\hline H5 & 1989 & 13 & 44 \\
\hline H10 & 1973 & 31 & 61 \\
\hline H12 & 1982 & 28 & 52 \\
\hline H13 & 1988 & 23 & 54 \\
\hline H14 & 1982 & 28 & 50 \\
\hline H16 & 1989 & 22 & 42 \\
\hline H17 & 1993 & 17 & 45 \\
\hline H18 & 1987 & 12 & 47 \\
\hline H20 & 1988 & 23 & 35 \\
\hline
\end{tabular}

* As letras H e M correspondem ao sexo do(a) entrevistado(a), sendo H para homens e $\mathrm{M}$ para mulheres

Fonte: Dos autores

A triangulação de técnicas é uma característica desejável nesse tipo de pesquisa, de modo a aprimorar a validade, obtendo dados de diferentes fontes (SILVERMAN, 2005; LÜDORF, 2004). Sendo assim, além das entrevistas baseadas em um roteiro de questões semiestruturado $^{1}$, foram realizadas observações do ambiente das academias. Anotar fatos e aspectos observados no diário de campo pode auxiliar nas interpretações (FONTANELLA et al., 2006; DUARTE, 2002). Os dados coletados foram analisados com base

${ }^{1} \mathrm{O}$ roteiro para as entrevistas foi previamente validado a partir da avaliação de cinco doutores especialistas na área, além da realização de algumas entrevistas piloto. Desse modo, compreendeu as seguintes questões: 1. Como tem sido sua trajetória como profissional de Educação Física atuante em academias de ginástica? 2. Você percebe alguma diferença na sua prática profissional no início da carreira e na de agora? 3. O que significa envelhecer para você? 4. Você tem alguma preocupação em relação ao seu envelhecimento? 5. De que maneira o envelhecimento se relaciona com sua vida profissional? 6. Como você se sente em relação ao seu corpo e à sua profissão, com o passar dos anos? 7. Você toma algum cuidado em relação ao seu processo de envelhecimento?

Movimento, Porto Alegre, v. 20, n. 4, p. 1523-1541, out./dez. de 2014. 
na análise de conteúdo proposta por Turato (2003), ao ressaltar a necessidade das respostas serem agrupadas em torno de temáticas mais amplas, respeitando os critérios de repetição e de relevância. As temáticas centrais geradas, que nortearão a apresentação dos dados, foram: concepções sobre o envelhecimento (degradação do físico; conhecimento e experiência); corpo, competência profissional e trabalho; cuidados com o corpo; satisfação profissional.

O estudo foi aprovado pelo Comitê de Ética em Pesquisa do Instituto de Estudos de Saúde Coletiva da Universidade Federal do Rio de Janeiro - IESC/UFRJ (processo $n^{\circ} 52 / 2008$, parecer $n^{\circ}$ 04/2009).

\section{ApresentAÇÃo E discussão dos dados}

Com relação ao envelhecer, detectou-se simultaneamente a ocorrência de dois processos. O primeiro ligado ao que podemos denominar de "degradação do físico":

Cara, vou te dizer o seguinte, num aspecto como físico, não é nada bom. Sei lá, é você sentir a degeneração do seu corpo com relação ao que era. Antigamente a gente tinha um preparo físico total, hoje em dia você sente dor no ombro, na lombar, você sente coisas que te atrapalham no dia a dia. (H2)

É você ficar cheio [...] é ficar enrugado, de repente uma "artrosezinha" ali ou ali, ou de repente alguma mazela que você adquire por algum excesso que você fez no passado, entendeu? E por aí é pra mim isso que é ir envelhecendo. (H5)

Envelhecer como pessoa é eu não conseguir ter algumas habilidades diárias... como a gente vê alguns alunos com certas dificuldades, de sentar, levantar, deitar, eu acho que o envelhecer pra mim é isso. Óbvio que tem a estética, não vou falar que não, eu sou mulher, a gente é muito mais cobrada na estética, mas eu acho que o pior é o teu corpo não ta funcionando né? Tentar levantar, deitar, andar, isso que eu acho que é uma das coisas que me preocupa muito. (M2)

Movimento, Porto Alegre, v. 20, n. 4, p. 1523-1541, out./dez. de 2014. 
A gente entra numa curva ascendente até os 24 , 25 anos de [...] o grande anabolismo e de repente as reações começam a ser mais catabólicas, você começa a descer a escada. (H13)

A partir dos depoimentos, percebe-se o envelhecer associado a elementos considerados negativos: ao declínio das funções biológicas, o que pode contribuir para diminuir a destreza e/ou aumentar a dificuldade na realização de tarefas; às dores, doenças e mudanças negativas na aparência.

A relação entre a atuação do profissional de Educação Física no ambiente das academias de ginástica e uma possível queda na capacidade física diante do passar dos anos deve ser considerada, uma vez que sua atividade laboral requer muitas vezes um elevado esforço físico. Espírito-Santo e Mourão (2006), por exemplo, observam que nas modalidades do fitness exige-se dos profissionais de Educação Física uma ótima aptidão física, pois em muitos casos é importante além de conduzir a sessão, realizá-la juntamente com a turma. No mesmo sentido, Palma e Assis (2005) ressaltam a importância de um adequado condicionamento físico para o profissional de Educação Física atuante em academia de ginástica, e alertam sobre a possibilidade de tal exigência induzi-lo a utilizar substâncias químicas que melhorem o desempenho.

Ponto que se destacou durante a coleta de dados do presente estudo e que contribui com o argumento de desgaste físico vivenciado por esses profissionais nesse mercado foi o pouco tempo disponível para o agendamento das entrevistas. Com efeito, acumulam trabalhos em escolas, clubes ou diferentes academias de ginástica. Observe-se assim que a atividade laboral, correlata às diferentes frentes de trabalho que permitem uma melhor remuneração, ao desgaste ocasionado pelo deslocamento entre as mesmas, aos horários irregulares, pode implicar em consequências corporais.

Já o segundo processo detectado referente ao envelhecimento está relacionado ao conhecimento e à experiência: 
$\mathrm{Eu}$ conto com isso (experiência profissional), de saber lidar com determinadas situações que às vezes o profissional que se formou (agora) não vai saber lidar; ele pode até tecnicamente ser melhor que eu, mas ele não vai saber lidar com aquela situação, porque a vida é feita de improvisos, né? Uma hora ou outra você vai ter que lidar com uma situação que você não aprendeu em um curso ou em nenhuma faculdade, você aprendeu com a vida. Então eu acho que está mais relacionado a isso, entendeu? Experiência de vida e dentro da sua profissão. (H5)

Você fica mais seguro por estar mais maduro, e por ter vivenciado muitas situações, então isso te dá mais... mais... uma certa segurança... e... e acho que é isso, mais conhecimento né? Porque você também, querendo ou não, não é nem por causa das graduações ou [...] não, é porque é conhecimento de dia a dia, conhecimento de lidar com as pessoas, né? Trabalhar com outras pessoas [...], acho que é um aprendizado de vida, não é que é só específico da carreira, não, porque eu me sinto assim com meus amigos, na rua, eu escuto mais. (H14)

Mais no comecinho, no comecinho eu errava muito a dosagem das aulas, muito forte, muito fraco e hoje eu acerto muito mais do que (antigamente), a gente nunca está perfeito, mas hoje praticamente são pouquíssimos erros. (H20)

Para o entrevistado 5, o passar dos anos lhe proporcionou mais experiência para lidar com situações imprevistas, ao mesmo tempo em que reconhece as possibilidades técnicas do profissional mais jovem. O entrevistado 14 credita ao envelhecimento um conhecimento vivencial que favorece mais segurança e maturidade para lidar com as pessoas, enquanto que o entrevistado 20 assinala a habilidade profissional quando comparada ao início de sua carreira, associada à avaliação da intensidade do trabalho estipulado.

Em certo sentido, os depoimentos nos remetem para o que observa Coelho Filho (1997) sobre o avanço da idade vir a ser 
considerado positivo se a experiência de vida promover mudanças na pessoa e na prática do profissional de ginástica em academias. De todo modo, apesar dos profissionais entrevistados demonstrarem valorizar certos aspectos relacionados ao envelhecimento, estudos anteriores apontam para uma realidade onde esta "experiência" pode não ser fundamental. Vilhena et al. (2012) salientam que a entrada e a continuidade do profissional atuante no mercado das academias estão associadas à capacidade deste se enquadrar na forma corporal padrão, sendo esta habilidade (ou predisposição) compreendida como símbolo de competência.

A equivocada associação entre aparência e competência, presente no senso comum, é também uma preocupação dos profissionais, como exemplificado no trecho a seguir:

Há um preconceito com relação à idade e há um preconceito com relação ao corpo, os professores gordos não são contratados [...]. Então, às vezes o preconceito ele vem...; olha aí, olha a gente mostrando a sociedade, o preconceito é do cliente, o cliente é preconceituoso, aí se o gestor da academia entrar nessa onda ele passa a ser por tabela: "não, eu vou agradar o cliente, vou botar o cara 'saradão' jovem para agradar o cliente" (H18)

Além disso, uma suposta preferência dos praticantes por profissionais mais jovens também poderia, eventualmente, contribuir para esse processo:

No meu caso da academia, é claro que é muito melhor para academia contratar um recémformado de vinte anos por várias questões; questão de visual porque é uma e... a pessoa tá mais disposta quando é mais nova, está mais disposta pra fazer coisas que quando você tiver trinta, quarenta, tiver um tempo já de profissão você não tá a fim de fazer... Não só fisicamente, como monetariamente; e os alunos da academia falam que eles preferem professor novo porque ninguém vai querer um quarentão, cinquentão numa sala de musculação, numa sala de ginástica

Movimento, Porto Alegre, v. 20, n. 4, p. 1523-1541, out./dez. de 2014. 
dando aula, é claro que eles vão preferir uma pessoa mais nova, seja homem ou mulher. (H16)

Eu tento me ver daqui a 15 anos dando aula ainda, tentando me ver com 60 anos, se eu vou ser aceito pelos alunos, não os mais velhos, porque os mais velhos vão comigo para sempre, mas, assim, um aluno novo entrando na academia e ver um coroa dando aula ali: "Não vou fazer com o coroa ali, vou fazer com um garoto ali que vai ser melhor" (pensamento do aluno na escolha de professor). Eu não sei como vai ser a comparação, olhando para minha cara e ao mesmo tempo em termos de, de..., se eu for ter a mesma disposição; eu gosto muito do meu trabalho, mas eu não sei daqui a 10 (anos), 15 (anos) como eu vou estar. Como a minha cabeça vai estar? [...] Eu tento manter uma certa postura, uma certa... que impõe um certo respeito para os alunos: "Pô, o cara está coroa ali, mas está mais ou menos inteiro!

Palma e Assis (2005) afirmam que, para o profissional de Educação Física atuante com o fitness, o corpo se apresenta como um produto nas relações de mercado, contribuindo como recurso técnico e físico. Importa ainda atentar para o fato de que, no mercado das grandes academias da cidade do Rio de Janeiro, experiência e competência técnica parecem não garantir prestígio e estabilidade ao profissional de ginástica, e sim a juventude associada à competência (COELHO FILHO, 2001; 2005). Segundo os entrevistados, tanto a academia (administração) quanto os próprios clientes demonstram preferência por profissionais mais jovens. Impulsionados pela busca da estabilidade financeira e aspirações relacionadas à carreira, os profissionais recém-inseridos no contexto das academias mostram-se mais dispostos fisicamente e submissos a situações desagradáveis, contudo, se sobressaem principalmente por motivos relacionados à aparência.

Ao pensar a academia como um negócio, como de fato é (FURTADO, 2007), os profissionais recém-formados normalmente ascendem ao mercado de trabalho como uma mão de obra mais barata. Conforme levantou Coelho Filho (2005), percebe-se nos

Movimento, Porto Alegre, v. 20, n. 4, p. 1523-1541, out./dez. de 2014. 
entrevistados certa insegurança quanto ao desenvolvimento da carreira com o avançar da idade, principalmente por estarem se distanciando do perfil estereotipado de profissional de Educação Física atuante em academia de ginástica, "jovem e sarado". Por conta do desgaste provocado pelo avançar da idade, parece ocorrer um afastamento de parte desses profissionais do mercado de trabalho em academias (principalmente as de grande porte) com o passar dos anos.

Diante dessas questões, o envelhecimento parece se colocar como um aspecto contraproducente na carreira do profissional de Educação Física atuante no mercado das academias de ginástica. Dessa maneira, na tentativa de manutenção da saúde, cuidados vinculados ao processo de envelhecimento são relatados:

Dificilmente eu vou envelhecer, porque eu sempre estou me mexendo, fazendo as minhas trilhas, eu faço a minha "malhaçãozinha" básica, mais fácil, não quero ficar forte, "bombado", entendeu? Mas faço pra eu me mexer, para as articulações se mexerem, meus músculos mexerem, meu sangue irrigar, entendeu? (H5)

Você começa a descer a escada, e o que a gente pode fazer pra reverter a entropia, que é uma entropia não só nossa, como a do próprio universo, a gente deve fazer através da atividade física, da alimentação, do sono e do..., de todos os mecanismos que a gente tem para manter e reverter isso. [...] eu me alimento bem, eu bebo água e todas as outras coisas que a gente sabe como professor, e tem que fazer. Tomo cerveja também, tomo vinho, não sou santo, entendeu? Mas não é todo dia, e todo dia é uma alimentação legal, procuro comer de três em três horas, muita fruta, legume e tal [...]. Então, eu sei fazer as minhas coisas da melhor maneira. (H13)

Eu me alimento bem, eu tenho as minhas vitaminas que eu tomo, as vitaminas que eu faço de liquidificador, nada de comprar, eu boto meu, as minhas verduras, laranja, eu faço as minhas maluquices lá e procuro comer de tudo bem, de tudo um pouco, e também me libero de vez em

Movimento, Porto Alegre, v. 20, n. 4, p. 1523-1541, out./dez. de 2014. 
quando, estou livre para comer meus camarões fritos, friturinhas, doces, as coisas que eu gosto, nada em exagero, nada em exagero, tudo de maneira equilibrada; procuro dormir bem, procuro acordar, acordo sempre na mesma hora, durmo sempre na mesma hora [....]; praticar um esporte, eu faço a minha (Ginástica Localizada). (H20)

Silva e Lüdorf (2012) identificaram em graduados em Educação Física atuantes em diferentes âmbitos uma preocupação em manter a funcionalidade corporal, uma vez que esta seria importante para desempenhar determinados papéis sociais relacionados à profissão. Nesse sentido, os entrevistados buscam, através da prática equilibrada de determinados cuidados, atrelados à exercitação física, à alimentação e às horas regulares de sono diárias, combater estes aspectos relacionados à "degradação do físico". Com esse objetivo, portanto, o profissional de Educação Física atuante em academias de ginástica acaba incorporando algumas das práticas corporais que tanto preconiza para os clientes dessas instituições.

Lupton (2000) alega que a saúde é vista como um objetivo a ser conquistado através de esforço e dedicação, tendo a atividade física um valor central. Para Ortega (2010), o homem dito como saudável contemporaneamente desenvolve uma série de preocupações (e consequentemente práticas/hábitos) físicas e estéticas. A ideia de "autogestão da saúde", também utilizada pelo autor, colabora para compreender tal comportamento constatado nos profissionais entrevistados, que se colocam responsáveis pela melhora e manutenção da própria saúde. O que vale questionar com relação ao constatado é até que ponto esses "hábitos" podem, por si só, de fato, garantir uma boa saúde e, além disso, postergar, ou até mesmo evitar, como acreditam os profissionais, marcas corporais representadas como negativas advindas do processo de envelhecimento.

Apesar de a literatura e dos achados do presente estudo relatarem certa resistência e algumas dificuldades que permeiam a 
carreira e a prática dos profissionais de Educação Física atuantes em academias de ginástica, correlatas ao processo de envelhecimento, emergiu nos discursos um considerável nível de satisfação com a prática da profissão, mesmo após décadas de formados:

Financeiramente não é uma profissão que para mim vale a pena, vale a pena pelo retorno, pela minha saúde que eu aprendi a controlar mais isso, a questão do exercício, da alimentação, do modo de vida que você tem. (H12)

Eu não vivo só de Educação Física, mas eu vivo muito a Educação Física, porque eu gosto muito, tanto que depois de velho, ou seja, com mais... com mais idade eu voltei a abraçar (a profissão). (H13)

Gosto de trabalhar em academia também, porque eu acho legal, eu acho um ambiente bacana, os resultados você consegue, é bacana... [...] Então eu acho que isso é legal, de você ter o retorno disso, ver que as pessoas, ensinar coisas que... que... que vão servir para ela, assim, não na academia, mas para vida dela [...] se sentir melhor. (H14)

Quando eu me formei eu já vi que era a ginástica localizada, ia ser a academia. Trabalhei já com musculação um pouco, mas eu gosto de salão (aula de ginástica localizada), gosto de salão, galera, música, ritmo. [...] eu gosto muito do meu trabalho. (H20)

Eu hoje em dia gosto muito do que eu faço, adoro. (M2)

Apesar da aparente contradição e dos aspectos intervenientes que podem alterar a vivência na carreira e na prática do profissional de Educação Física ao longo de seu envelhecimento, a academia de ginástica se constitui em um dos principais locais de trabalho para essa classe (ESPIRITO-SANTO; MOURÃO, 2006). Da mesma maneira que há indícios que poderiam corroborar o argumento de Palma et al. (2007) acerca de uma "aposentadoria precoce" por parte desses profissionais, parecem haver ainda determinados nichos de mercado oportunos aos que possuem mais tempo de

Movimento, Porto Alegre, v. 20, n. 4, p. 1523-1541, out./dez. de 2014. 
carreira, como, por exemplo, cargos de coordenação ou atuação como personal trainer (LÜDORF; ORTEGA, 2013).

Mesmo que o passar dos anos possa ser considerado um fator não tão favorável à atuação do profissional de Educação Física em academias de ginástica, estes espaços ainda parecem atender, de algum modo, aqueles que se mantêm nesse mercado após anos ou décadas. A satisfação com a profissão expressada pelos entrevistados não abarca a questão financeira, que emerge como mais uma adversidade nesse âmbito de trabalho. Por outro lado, é uma satisfação proporcionada, sobretudo, pelo ambiente agradável de trabalho, pelos relacionamentos interpessoais e por lidar com hábitos saudáveis. Apesar das dificuldades relacionadas ao desgaste físico e aos estereótipos corporais, alguns desses profissionais ainda se revelam convictos da profissão que escolheram. Vale lembrar que não havia no roteiro nenhuma questão específica que estimulasse os entrevistados a abordar essa temática. Ao contrário, a demonstração de satisfação com o labor emergiu espontaneamente nos discursos, o que ressalta ainda mais a relevância de seu conteúdo.

\section{Conclusão}

Em linhas gerais, para os entrevistados, o envelhecimento representa um declínio de aspectos como condicionamento cardiovascular, força e disposição, acompanhado de um acúmulo de experiência, de conhecimentos de vida e da profissão. O desgaste referente ao esforço físico e à longa jornada de trabalho, em busca de uma melhor remuneração, muitas vezes desmotiva e afasta profissionais do mercado com o avançar da idade. Como forma de minimizar danos subjetivos vinculados à perda de espaço profissional, detectou-se investimento em diversos cuidados corporais, na opinião dos entrevistados, para minimizar os efeitos do processo de envelhecimento.

Deixar de representar o modelo jovem, saudável e bem disposto, tão apreciado e idealizado socialmente no âmbito das academias, emerge como um ponto negativo para os profissionais

Movimento, Porto Alegre, v. 20, n. 4, p. 1523-1541, out./dez. de 2014. 
entrevistados. Em termos de gestão, privilegiam-se profissionais mais jovens e com remunerações mais baixas. O afastamento gradativo do modelo de corpo idealizado para o profissional de Educação Física atuante em academias de ginástica parece afetar a relação que o mesmo mantém com frequentadores dessas instituições, principalmente os mais jovens, uma vez que se mostram mais vulneráveis a eleger modelos. Portanto, tal como descreve Coelho Filho (2005), o profissional de Educação Física atuante em academias de ginástica, ao considerar, num sistema projetivo, que ele próprio funciona para os frequentadores dessas instituições como um espelho deformador, visto que não reflete o sujeito, mas sim um modelo ideal (e normativo), tem consciência de que as exigências de estética corporal e desempenho físico tolhem progressivamente suas possibilidades de crescimento nesse mercado de trabalho (de acordo com o avanço na idade).

Embora demonstrem dificuldades associadas ao envelhecer nas academias de ginástica, foi possível encontrar profissionais que se mostram convictos da escolha em trabalhar nesse mercado, principalmente por estarem comprometidos e vivenciando um determinado estilo de vida ativo ligado à saúde e aos saberes da profissão.

Diante dos distintos papéis encarados pelo profissional de Educação Física em academias de ginástica (musculação, modalidades coletivas de ginástica, personal trainer etc.), sugere-se como possibilidade de estudos futuros investigar as particularidades relacionadas ao envelhecimento do mesmo em suas diferentes atribuições dentro dessas instituições. 


\begin{abstract}
Aging in the view of Physical Education professionals working at fitness centers: body and profession

Abstract: The aim of this study is to understand how the Physical Education professionals working at fitness centers see and deal with their own aging, as well as to debate possible relations with regard to aging, the body and the labor market for fitness centers. Data were collected through semi-structured interviews. Ceasing to match the young and healthy model admired at fitness centers is negative to those professionals, who seek the knowledge acquired in the profession to cover up stereotypes associated with aging. Thereby, they believe they increase their chances of remaining in the market.

Keywords: Fitness Centers. Faculty. Physical Education. Aging. Body.
\end{abstract}

\section{REFERÊNCIAS}

ANTUNES, A. C. Perfil profissional de instrutores de academias de ginástica e musculação. EFDeportes.com, Revista Digital, Buenos Aires, v.9, n.60, 2003. Disponível em: http://www.efdeportes.com/efd60/perfil.htm. Acesso em: 28 mar. 2014.

BAUER, M. W.; AARTS, B. A construção do corpus: um princípio para a coleta de dados qualitativos. In: BAUER, M. W.; GASKEL, G. (ed.). Pesquisa qualitativa com texto, imagem e som: um manual prático. 2. ed. Trad. Pedrinho A. Guareschi. Petrópolis,RJ: Vozes, 2003. p. 39-63. 
COELHO FILHO, C. A. A. Fruto maduro? Caindo do pé? In: TORRES, M.; SANTOS, R. F. dos (orgs.). Lições de educação física 1. Rio de Janeiro: UniverCidade, 2005. p. $165-202$.

COELHO FILHO, C. A. A.. O discurso do profissional de ginástica em academia no Rio de Janeiro. Movimento, Porto Alegre, v. 6, n.12, p.14-24, jul./dez. 2001. Disponível em: http://seer.ufrgs.br/Movimento/article/view/2496. Acesso em: 28 mar. 2014.

COELHO FILHO, C. A. A.. Competências básicas necessárias ao profissional de ginástica em academia. In: COSTA, V. L. de M. Formação profissional universitária em educação física. Rio de Janeiro: UGF, 1997. p. 127-160.

CROSSLEY, N.. In the Gym: Motives, Meaning and Moral Careers. Body \& Society, London, v.1, n.3, p.23-50, 2006. Disponível em: http://bod.sagepub.com/ content/12/3/23.abstract. Acesso em: 28 mar. 2014.

DUARTE, R. Pesquisa qualitativa: reflexões sobre o trabalho de campo. Cadernos de Pesquisa [online], Rio de Janeiro, n.115, p. 139-154, mar. 2002. Disponível em: http://www.scielo.br/scielo.php?pid=S0100-15742002000100005\&script=sci_ abstract\&tlng=pt. Acesso em: 28 mar. 2014.

ESPIRITO-SANTO, G.; MOURÃO L. A auto-representação da saúde de professores de Educação Física de academias. Revista Brasileira de Ciências do Esporte, Campinas, v.27, n.3, p.39-55, maio. 2006. Disponível em: http://rbceonline.org.br/ revista/index.php/RBCE/article/view/73. Acesso em: 28 mar. 2014.

FREITAS, D. C.; SILVA, A. C.; LÜDORF, S. M. A. O professor de Educação Física e sua visão de corpo: academias de ginástica em foco. EFDeportes.com, Revista Digital, Buenos Aires, v. 16, n.155, abr./jun. 2011. Disponível em: http://www. efdeportes.com/efd155/visao-de-corpo-academias-de-ginastica-em-foco.htm. Acesso em: 28 mar. 2014.

FREITAS, D. C.; SILVA, A. C.; LÜDORF, S. M. A. As práticas corporais nas academias de ginástica: um olhar do professor sobre o corpo fluminense. Revista Brasileira de Ciências do Esporte, Florianópolis, v. 33, n.4, p.959974, out./set. 2011a. Disponível em: http://www.scielo.br/scielo.php?script=sci_ arttext\&pid=S0101-32892011000400011. Acesso em: 28 mar. 2014.

FONTANELLA, B. J. B.; CAMPOS, C. J. G.; TURATO, E. R. Data collection in clinical-qualitative research: use of non-directed interviews with open-ended questions by health professionals. Revista Latino-americana de Enfermagem. Ribeirão Preto, v.14, n.5, p. 812-820, set./out. 2006. Disponível em: http://www. scielo.br/scielo.php?pid=S0104-11692006000500025\&script=sci_arttext. Acesso em: 28 mar. 2014.

FURTADO; R. P. Novas tecnologias e novas formas de organização do trabalho do professor nas academias de ginástica. Pensar a Prática, Goiânia, v.10, n.2, p. 307322, jul./dez. 2007. Disponível em: http://www.revistas.ufg.br/index.php/fef/article/ view/1110. Acesso em: 28 mar. 2014.

Movimento, Porto Alegre, v. 20, n. 4, p. 1523-1541, out./dez. de 2014. 
GASKELL, G. Entrevistas individuais e grupais. In: BAUER, M. W.; GASKEL, G. (Ed.). Pesquisa qualitativa com texto, imagem e som: um manual prático. 2. ed. Trad. Pedrinho A. Guareschi. Petrópolis, RJ: Vozes, 2003. p. 64-89.

GOLDENBERG, M. Coroas: corpo, envelhecimento, casamento e infidelidade. Rio de Janeiro: Record, 2008.

LIZ, C. M.; CROCETTA, T. B.; VIANA, M. S.; BRANDT, R.; ANDRADE, A. Aderência à prática de exercícios físicos em academias de ginástica. Motriz, Rio Claro, v. 16, n. 1, p. 181-188, jan./mar. 2010. Disponível em: http://www.periodicos.rc.biblioteca. unesp.br/index.php/motriz/article/viewFile/1980-6574.2010v16n1p181/2882. Acesso em: 28 mar. 2014.

LÜDORF, S.M.A.; ORTEGA, F.J.G. Marcas no corpo, cansaço e experiência: nuances do envelhecer como professor de Educação Física. Interface, Botucatu, v.17, n.46, p. 661-675, jul./set. 2013. Disponível em: http://www.scielo.br/scielo. php?pid=S1414-32832013000300013\&script=sci_abstract. Acesso em: 28 mar. 2014.

LÜDORF, S. M. A.. Metodologia da pesquisa: do projeto à monografia. Rio de Janeiro: Shape, 2004.

LUPTON, D. Corpos, prazeres e prática do eu. Educação \& Realidade, Porto Alegre, v.25, n.2, p. 15-48, jul./dez. 2000.

MARCELLINO, N. C. academias de ginásticas como opção de lazer. Revista Brasileira de Ciência e movimento, Brasília, v. 11, n. 2, p. 49-54, jun. 2003. Disponível em: http://www.cdof.com.br/ARTIGOS/DIVERSOS/Academias $\% 20$ de\%20gin\%E1stica\%20como\%20op\%E7\%E3o\%20de\%20lazer.pdf. Acesso em: 28 mar. 2014.

NOVAES, J. Estética: o corpo na academia. Rio de Janeiro: Shape, 2001.

ORTEGA, F.; ZORZANELLI, R. Corpo em evidência: a ciência e a redefinição do humano. Rio de Janeiro: Civilização Brasileira, 2010.

PALMA, A.; JARDIM, S.; LUIZ, R. R.; SILVA FILHO, J.F. Trabalho e saúde: o caso dos professores de Educação Física que atuam em academias de ginástica. Cadernos IPUB (UFRJ), Rio de Janeiro, v. 13, p. 11-30, jan. 2007.

PALMA, A.; ASSIS, M.; Uso de esteróides anabólico-androgênicos e aceleradores metabólicos em professores de Educação Física que atuam em academias de ginástica. Revista Brasileira de Ciências do Esporte, Campinas, v.27, n.1, p.7592, set. 2005. Disponível em: http://rbceonline.org.br/revista/index.php/RBCE/ article/view/135. Acesso em: 28 mar. 2014.

ROJAS, P. N. C. Aderência aos programas de exercícios físicos em academias de ginástica na cidade de Curitiba-PR. 2001. 112 f. Dissertação (Mestrado em Educação Física) - Departamento de Educação Física, Universidade Federal de Santa Catarina, Florianópolis, 2003.

Movimento, Porto Alegre, v. 20, n. 4, p. 1523-1541, out./dez. de 2014. 
O envelhecer na visão do profissional de Educação Física...

SASSATELLI, R. Interaction order and beyond: A field analysis of body culture within fitness gyms. Body \& Society, London, v. 5, n. 2-3, p. 227-248, 1999. Disponível em: http://bod.sagepub.com/content/5/2-3/227.abstract. Acesso em: 28 mar. de 2014.

SILVA, A. C.; LÜDORF, S. M. A. Possíveis relações entre corpo, saúde e o envelhecimento do professor de Educação Física. Movimento, Porto Alegre, v. 18, n. 2, p. 187-204, abr./jun. 2012. Disponível em: http://seer.ufrgs.br/Movimento/ article/view/18807. Acesso em: 28 mar. 2014.

SILVERMAN, D. Doing qualitative research: a practical handbook. 2. ed. London: Sage, 2005.

TOSCANO, J. J. O. Academia de ginástica: um serviço de saúde latente. Revista Brasileira de Ciência e Movimento, Brasília, v. 9, n. 1, p. 40-42, jan. 2001. Disponível em: http://seer.ufrgs.br/Movimento/article/view/18807. Acesso em: 28 mar. 2014.

TURATO, E. R. Tratado da metodologia da pesquisa clínico-qualitativa: construção teórico-epistemológica, discussão comparada e aplicação nas áreas da saúde e humanas. 2.ed. Petrópolis, RJ: Vozes, 2003.

TURATO, E. R.. Métodos quantitativos e qualitativos na área da saúde: definições diferenças e seus objetivos de pesquisa. Revista de Saúde Pública, Rio de Janeiro, v. 37, n. 3, p. 507-514, jul./set. 2005. Disponível em: http://www.scielo.br/ pdf/rsp/v39n3/24808.pdf. Acesso em: 28 mar. 2014.

VILHENA, L. M.; SANTOS, T. M.; PALMA, A.; MOURÃO L. Avaliação da imagem corporal em professores de Educação Física atuantes no fitness na cidade do Rio de Janeiro. Revista Brasileira de Ciências do Esporte, Florianópolis, v. 34, n. 2, p. 449-464, abr./jun. 2012. Disponível em: http://www.scielo.br/scielo.php?pid=S010132892012000200014\&script=sci_arttext. Acesso em: 28 mar. 2014.

\section{Endereço para correspondência}

Rua de Santana, nº 124, Ap. 1008

Centro, Rio de Janeiro, RJ

CEP: 20230261

Brasil

Recebido em:31.03.2014

Aprovado em:12.07.2014

Movimento, Porto Alegre, v. 20, n. 4, p. 1523-1541, out./dez. de 2014. 